\title{
PENDEKATAN 5S TERHADAP TOOLING SUPPLY DALAM PROSES MANUAL ASSEMBLY UNTUK MEREDUKSI TERJADINYA LOST TOOL
}

\author{
Risang Ardi Toni Pramudya \\ Fakultas Teknik, Program Studi Teknik Industri \\ Universitas Sebelas Maret \\ Email: risangatp@gmail.com \\ Pringgo Widyo Laksono \\ Fakultas Teknik, Program Studi Teknik Industri \\ Universitas Sebelas Maret \\ Email: pringgo@ft.uns.ac.id
}

\begin{abstract}
ABSTRAK
Perusahaan berusaha untuk terus menerus meningkatkan kinerja produktifitas dalam meningkatkan performa kerja dari berbagai elemen perusahaan. Di Indonesia masih banyak industri manufaktur baik kecil maupun yang sudah besar masih menggunakan manual assembly. Penggunaan manual assembly masih memiliki tingkat keberhasilan yang rendah dan proses yang memakan waktu lebih banyak dibandingkan assembly otomatis. Hal tersebut disebabkan karena dalam manual assembly membutuhkan operator yang mempunyai soft skill di bidangnya. Untuk itu penelitian ini membahas mengenai proses manual assembly dalam industri manufaktur. Salah satu bentuk kesalahan yang sering terjadi dalam proses manual assembly adalah penggunaan perkakas yang kurang tertata dalam area assembly sehingga sering terjadi insiden kehilangan peralatan kecil seperti kunci pas, kunci ring, obeng dll. Tooling supply merupakan salah satu metode yang dikembangkan oleh PT. XYZ untuk menyiapkan, mengatur dan memelihara bagaimana perkakas untuk bekerja dapat diterima dengan benar di area produksi dan dapat mengurangi waste sebanyak mungkin. Akan tetapi dalam proses berjalannya masih perlu perbaikan yang dapat mengoptimalkan fungsinya, salah satu pendekatannya ialah $5 \mathrm{~S}$. Pada pelaksanaan $5 \mathrm{~S}$ hanya seiton (rapi) dan seiso (resik) yang dapat diterapkan, sedangkan seiri (ringkas), seiketsu (rawat) dan shitsuke (rajin) belum dapat diterapkan karena adanya kendala yang terdapat di perusahaan.
\end{abstract}

Kata kunci: 5S, produktifitas, performa kerja, tooling management, tooling supply.

\begin{abstract}
The Company strives to continuously improve productivity performance in improving the work performance of various elements of the company. In Indonesia there are many manufacturing industries both small and large already using manual assembly. The use of manual assembly still has a low success rate and a process that takes more time than the automatic assembly. This is because in the manual assembly requires operators who have soft skills in the field. Therefore, this research discusses the process of assembly manual in manufacturing industry. One form of error that often occurs in the process of manual assembly is the use of tools that are less organized in the-area of assembly so often incident loss of small equipment such as wrenches, ring locks, screwdrivers and so on. Tooling supply is one method developed by PT. XYZ to set up, manage and maintain how tools to work can be received correctly in the production area and can reduce waste as much as possible. However, in the process of running still need improvement that can optimize its function, one approach is 5S. In the implementation of $5 S$ only seiton (set in order) and seiso (shine) are applicable, while seiri (sort), seiketsu (standardize) and shitsuke (sustain) can not be applied because of the constraints contained in the company.
\end{abstract}

Keywords: 5S, productivity, tooling management, tooling supply, work performance.

\section{PENDAHULUAN}

Persaingan antar perusahaan semakin sengit baik dalam hal otomotif, garmer, furniture maupun pelaayanan jasa. Dalam keberjalanannya, selalu dilakukan peningkatan untuk menjadikan perusahaan menjadi lebih baik dari sebelumya. Perusahaan harus menyiapkan strategi untuk bersaing dengan kompetitornya. Perkembangan dan kemajuan sebuah perusahaan juga dipengaruhi oleh kapabilitas perusahaan dalam memenuhi permintaan dan keinginan konsumen yang akan semakin meningkat dari 
waktu ke waktu [1]. Salah satu aspek untuk continuous improvement ialah dengan menerapkan standar sistem manajemen mutu atau quality management system (QMS). Salah satu penerapan QMS ialah dalam standarisasi berupa prosedur yang beraku diperusahaan. Fungsi prosedur tersebut untuk memperlancar tugas dari karyawan sebagai dasar dari perkerjaan dan dapat digunakan sebagai dasar hukum bila terjadi penyimpangan [2]. Dalam dunia assembly insiden hilangnya tool dapat menyebabkan FOD (Foreign Object Debris) yaitu substan yang dapat mengakibatkan bahaya ketika ada benda/alat yang tertinggal/terselip dalam produk rakitan. FOD sering terjadi pada produk rakitan yang memiliki volume yang besar seperti motor, mobil, truk, kapal, kereta dan pesawat.

PT. XYZ merupakan salah satu perusuhaan yang bergerak pada bidang transportasi udara seperti pembuatan dan perawatan mesin. Perusahaan ini berorientasi kepada continuous improvement untuk membawa diri kepada level internasional. Salah satu cara yang dilakukan perusahaan adalah mengembangkan standar yang berlaku diperusahaan, standar tersebut dapat berupa prosedur kerja karyawan. Salah satu prosedur yang menjadi mendukung pada perusahaan ini dalam melakukan final assembly sering disebut tooling supply. Tooling supply merupakan suatu metode untuk menyiapkan, mengatur dan memelihara bagaimana tools untuk bekerja dapat diterima dengan benar di lantai produksi dan mengurangi waste sebanyak mungkin dengan kegiatan ini. Tooling (perkakas) merupakan peralatan yang dibutuhkan untuk membantu proses pembuatan dan perakitan di area produksi.

Untuk mengembangkan prosedur yang baru dieprlukan teori dasar yang dapat memperlancar peekrjaan. Pendekatan grounded theory dapat digunakan pada hal-hal semacam ini. Grounded theory memiliki poin utama yaitu a) menekankan membangun sebuah teori dengan gagasan baru, b) berpendapat bahwa penelitian kualitatif dapat menghasilkan teori, c) melihat grounded theory sebagai metode untuk melakukan analisis prosesal (mengubah perilaku) yang ketat, d) menganjurkan menggunakan metode komparatif/membangdingkan selama proses analitik dan e) dimaksudkan untuk menyediakan alat khusus untuk membangun teori[3]. Proses assembly di bagian produksi sering terjadi kekurangan peralatan yang ada padahal bagian perencana sudah memberikan arahan berupa uraian pekerjaan dengan peralatan yang tercukupi. Pada proses ini secara periodik selalu terjadi hal seperti itu sehingga menyebabkan perkerjaan mengalami delay.

Permasalahan diatas merupakan salah satu bentuk dari waste, dimana aktivitas tersebut tidak memiliki nilai tambah dalam proses transformasi input menjadi output [4]. Perbaikan yang dilakukan bertujuan untuk menghilangkan pemborosan (waste) dan meningkatkan value added produk agar memberikan nilai kepada pelanggan (customer value) [5]. Lean manufacturing merupakan konsep dari Toyota Production System dengan tujuan untuk meningkatkan nilai tambah kerja dengan menghilangkan waste dan mengurangi pekerjaan yang tidak perlu, biaya yang lebih rendah, kualitas yang lebih tinggi dan lead time yang lebih pendek [6]. Dalam membentuk lean manufacturing dibutuhkan cara berfikir yang berfokus untuk menjadikan produk mengalir melalui tahapan yang memberikan nilai tanpa adanya hambatan (one piece flow), sebuah pull system yang bersumber dari permintaan customer untuk mencapai interval proses yang pendek dan membudayakan melakukan continuous improvement dengan tekun[7].

Untuk mengetahui penyebab terjadinya lost tool digunakan cause-effect diagram, dimana cause-effect diagram memiliki fungsi dasar meengidentifikasi dan mengorganisasi penyebab-penyebab masalah sehingga dapat memecahkan masalah tentag kualitas yang menjadi perhatian bagi perushaan [8]. Setelah penyebab masalah diidentifikasi selanjutnya melakukan pembobotan pada masalah dengan kriteria severity, occurence dan detection untuk dihitung nilai risk priority number (RPN). Nilai RPN ini dapat menunjukkan bahwa betapa gawatnya kelompok proses bila suatu kesalahan terjadi [9]. Dengan mengakumulasi presentase dari nilai tersebut digunakan analisa pareto dan membagi menjadi dua kelompok $20 \%$ dan $80 \%$. Perusahaan ingin melakukan pengembangan dengan perlahan-lahan sehingga permasalahan yang diangkat untuk menjadi bahan perbaikan adalah kelompok 20\%. Untuk memecahkan permasalahan tersebut digunakan metode 5S. Metode 5S (Seiri, Seiton, Seiso, Seiketsu, dan Shitsuke) ini pertama kali muncul pada tahun 1980 an yang digagas oleh Takashi Osada [10]. Metode 5S ini merupakan sebuah metode yang dapat digunakan untuk tujuan menciptakan dan menjaga kualitas lingkungan kerja dalam organisasi [11]. Metode 5S juga bertujuan untuk menjaga lingkungan kerja tetap aman, bersih, nyaman dan kondusif dan memiliki hubungan yang positif terhadap kualitas dan produktivitas [12]. Penerapan 5S harus memperhatikan konteks dan kebutuhan praktikal sebuah organisasi agar tujuan organisasi dapat tercapai [13]. Konsep khusus penerapan $5 \mathrm{~S}$ di organisasi penelitian penting dilakukan karena organisasi penelitian memiliki karakteristik kegiatan yang khas dan berbeda dengan jenis organisasi lainnya. Organisasi penelitian memiliki karakteristik dinamis dan melakukan hal-hal yang bersifat baru yang mengkategorikannya ke dalam bentuk organisasi organik [14]. 


\section{METODOLOGI PENELITIAN}

Berikut ini merupakan langkah-langkah dalam melakukan implementasi 5S ke dalam konsep tooling supply:

a. Melakukan pengamatan pada area assembly

Pengamatan ini dilakukan untuk mengetahui keadaan pada area assembly. Hal ini dilakukan untuk mengetahui apakah operator menerapkan konsep disiplin ketika melakukan pekerjaan. Untuk pembanding terhadap pengamatan, digunakan standard operating procedure yang terdapat di perusahaan.

b. Melakukan wawancara terhadap stakeholder

Wawancara ini bertujuan untuk memperkuat hipotesis awal sehingga mempermudah dalam menganalisis usulan yang tepat. Stakeholder yang bersangkutan antara lain operator, leader bagian assembly, supervisor dan bagian warehouse pengelola perkakas.

c. Pembuatan Cause-Effect Diagram

Hasil identifikasi tersebut dijadikan dasar untuk menyusun konsep penerapan 5S yang sesuai dengan karakteristik area assembly. Hasil identifikasi berupa layout kerja saat ini serta cause-effect diagram. Adanya resistansi yang mungkin timbul baik dari berbagai menjadi pertimbangan terkait penerapan 5S. Aspek ini perlu diperhatikan mengingat ada potensi resistansi terhadap masukkan yang baru baik dari beberapa pihak yang dapat berdampak pada kegagalan penerapan usulan tersebut [16]

d. Penerapan 5S

Setelah mengetahui penyebab dari beberapa masalah, langkah selanjutnya dilakukan pembuatan usulan terkait dengan masalah yang timbul di area assembly. Mengidentifikasi penyebab masalah yang diangkat kemudian mengklasifikasikannya sesuai dengan 5S (Seiri, Seiton, Seiso, Seiketsu, dan Shitsuke)

e. Hasil Penerapan 5S

Implementasi hasil 5S yang sudah dilakukan di area produksi.

\section{HASIL DAN PEMBAHASAN}

Berikut ini merupakan hasil dari pengolahan data yang dilakukan secara langsung maupun dengan wawancara. Pola pergerangan tool yang akan dikirim dari gudang ke area produksi hingga kembali ke gudang.

\subsection{Siklus Pergerakan Tool Di Area Assembly}

Pada area assembly, operator akan menggunakan tool yang sudah ada dalam trolley tersebut sesuai dengan susunan kerja yang telah diberikan. Trolley yang ditunjukkan oleh Gambar 1 berfungsi sebagai tempat meletakkan tool sehingga area assembly terlihat resik. Tool yang diisikan ke trolley berdasarkan jumlah kebutuhan pada area assembly tersebut dan isi dari trolley bisa lebih dari 20 jenis tool yang berbeda dengan berbagai ukuran. Setiap melakukan peminjaman tool, operator harus menukarnya dengan tanda peminjaman mereka dan operator juga mengenakan tool bag sebagai tempat meletakkan tool ketika dalam proses assembly. Tanda peminjam ini berfungsi untuk mengetahui operator mana yang sedang meminjam karena di area assembly ada lebih dari 8 operator.

Setiap pekerjaan selesai selesai tool yang sudah tidak digunakan harus dikembalikan ke trolley seperti sebelum dipinjam (maksimal sehari setelah selesai bekerja). Hal ini bertujuan untuk mempermudah pengecekan dan menghindari terjadinya kehilangan. Bagian gudang peralatan terkadang datang ke area produksi untuk melakukan pengecekan tool apakah rusak atau hilang, akan tetapi tidak punya kewenangan untuk menyatakan bahwa tool hilang. Sehingga bagian gudang hanya dapat melaporkan kejadiaan tersebut ke quality assurance dimana quality assurance mempunyai kewenangan untuk menyatakan bahwa tool tersebut hilang atau FOD. Leader atau quality assurance juga harus melakukan pengecekan terhadap tool di trolley untuk menyikapi jika terjadi kehilangan tool karena dapat menyebabkan FOD. Siklus pergerakan tool di area assembly dapat dilihat di Gambar 2. 


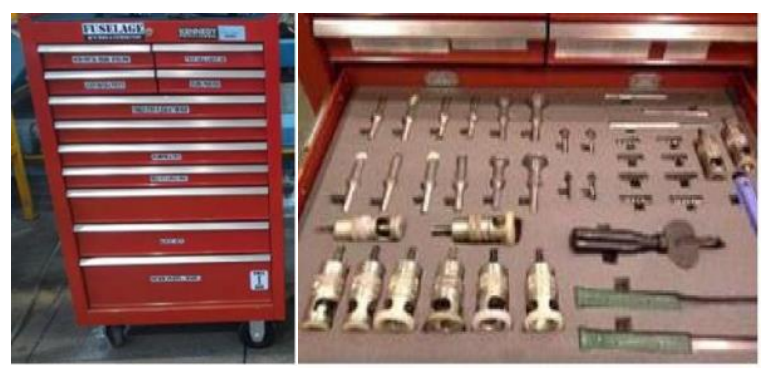

Gambar 1. Trolley

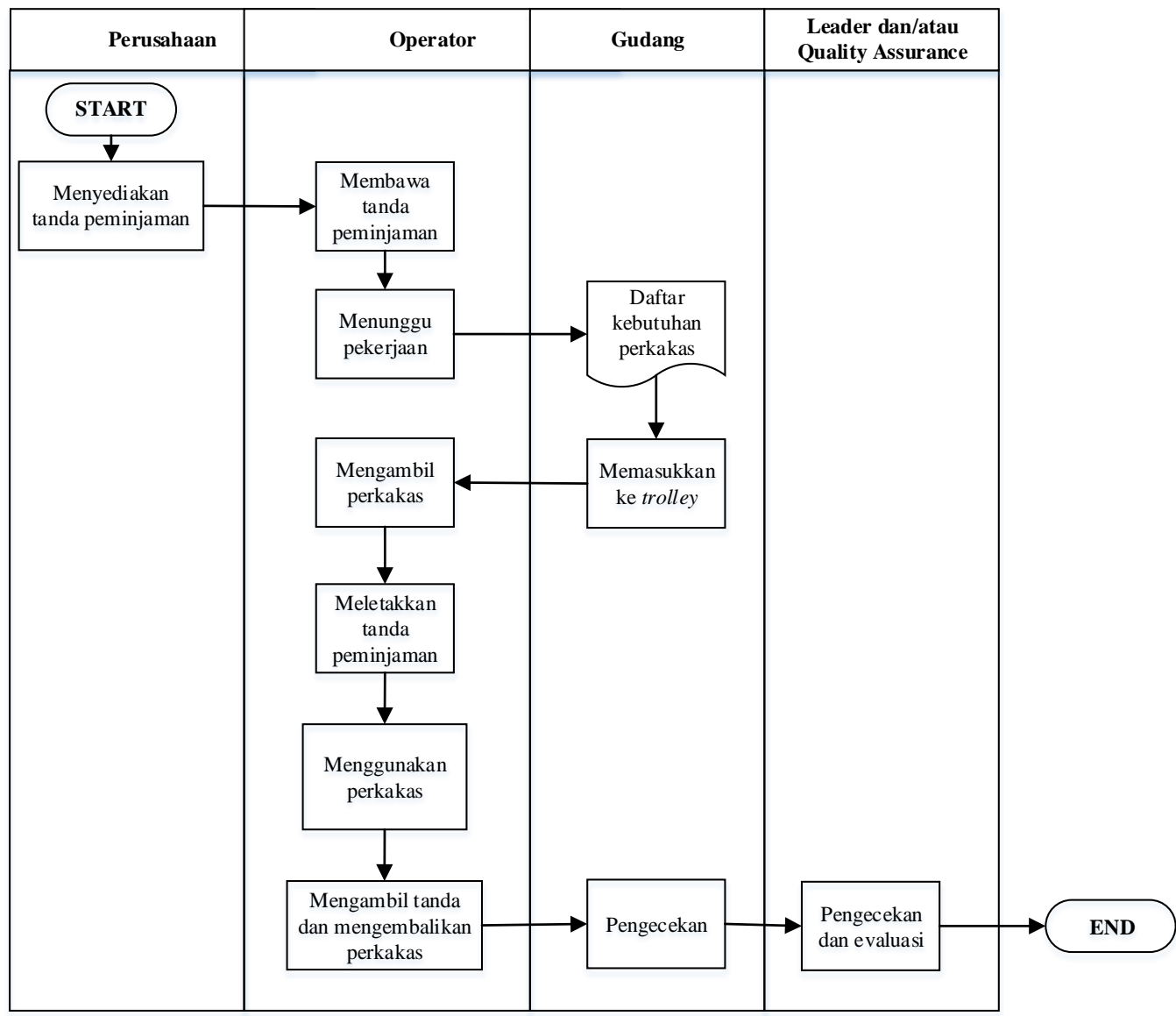

Gambar 2. Aliran Pergerakan Tool

\subsection{Data Histori Kehilangan Tool}

Pada Gambar 3 menyajikan data dari beberapa jenis tool yang digunakan dalam proses assembly yang berada di trolley pada pengecekan mingguan.

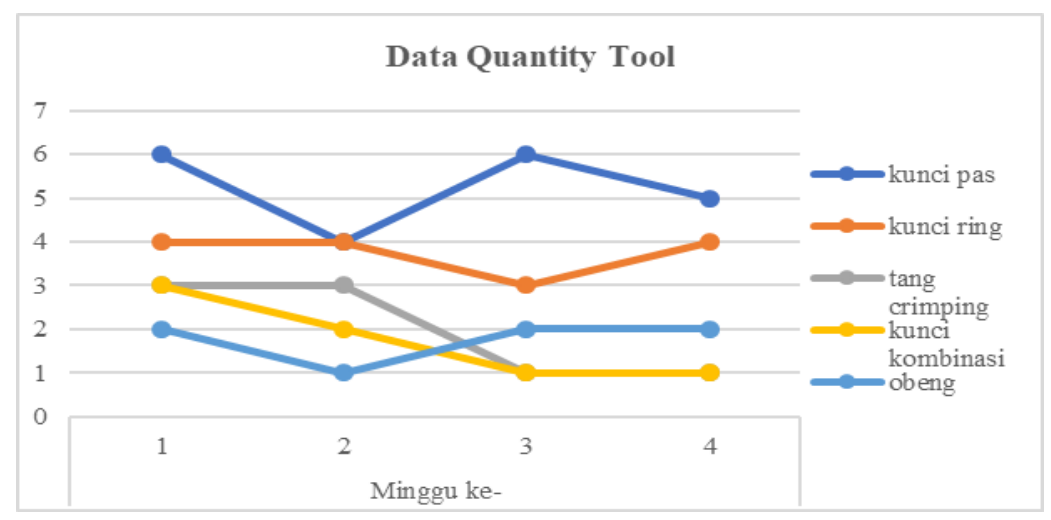

Gambar 3. Data Histori Pengecekan Mingguan 
Dari data pada Gambar 3 dapat dilihat bahwa jumlah tool tidak menentu, padahal jumlah tool yang berada di trolley seharunya tetap. Dari wawancara yang dilakukan diketahui bahwa operator jarang mengembalikan tool setelah selesai bekerja bahkan ada beberapa operator yang mengembalikan tool beberapa minggu hingga bulan kemudian. Operator sering kali lupa telah membawa tool tersebut karena sudah lama tidak dikembalikan. Hal ini berakibat pada terhambatnya proses assembly jika kebutuhan tool kekurangan. Sedangkan leader di area assembly dan quality assurance juga jarang melakukan pengecekan di trolley karena lebih fokus ke perkerjaan yang lain. Kejadian tersebut juga berkaitan dengan departemen metrologi karena setiap tool memiliki tanggal kalibrasi berbeda-beda. Jika tool tidak di kalibrasi sebelum tanggal jatuh tempo maka tool tersebut dinyatakan rusak dan tidak digunakan kembali. Tujuaannya agar perusahaan dapat bersaing di dunia internasional yang berlandaskan standarisasi. Hal ini berakibat pada bagian keuangan perusahaan.

\subsection{Cause-Effect Diagram}

Cause-effect diagram merupakan salah satu seven tool yang digunakan untuk mengidentifikasi berbagai sebab potensial dari suatu masalah dan menganalisis sebab tersebut. Pada Gambar 4 menyajikan cause-effect diagram berdasarkan hasil pengamatan dilapangan dan wawancara. Selanjutnya dilakukan pembobotan setiap masalahnya untuk dihitung nilai RPN (Risk Priority Number).

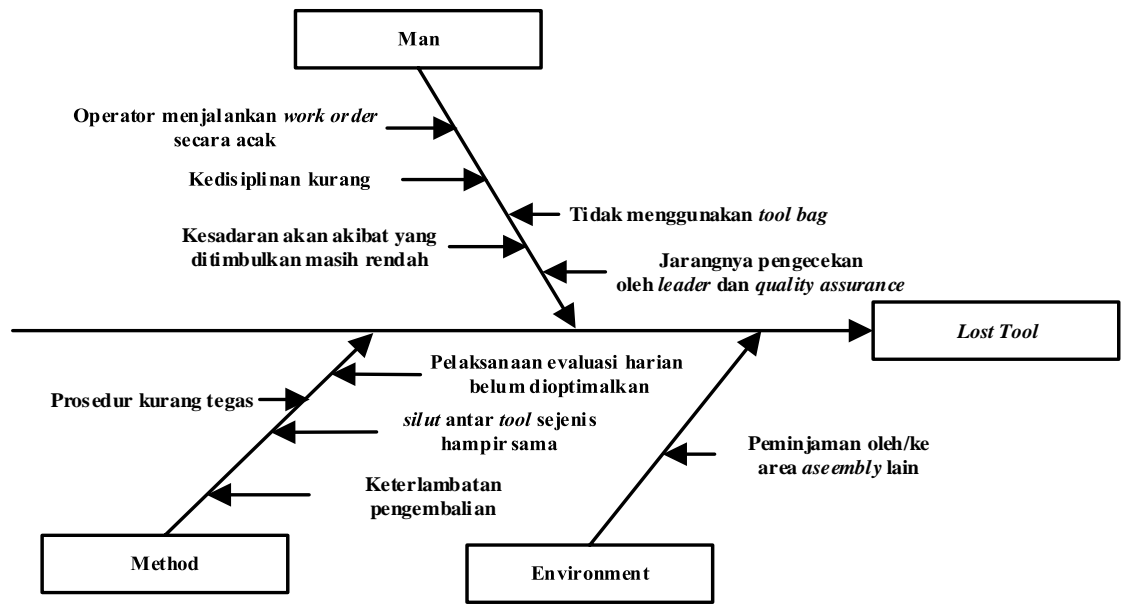

Gambar 4. Cause-Effect Diagram Lost Tool

Dari hasil penjabaran cause-effect diagram pada Gambar 4 dilakukan analisis pembobotan untuk mengetahui tingkat kritis dari masalahnya dan direpresentasikan dalam bentuk perhitungan nilai RPN. Untuk melakukan analisis nilai RPN ditentukan dengan menggunakan perkalian antara rating dari severity $(\mathrm{S})$, occurrence $(\mathrm{O})$ dan detection $(\mathrm{D})$. Rating tiga hal tersebut sebelumnya telah didiskusikan dengan pihak yang terkait sebagai monitoring bagian final assembly. Hasil pembobotan masing-masing masalah dapat dilihat di Tabel 1 dan presentase kumulatif dari pembobotan dapat dilihat di Tabel 2. Sedangkan untuk prioritas masalah yang akan diselesaikan akan ditampilkan di Tabel 3.

Tabel 1. Hasil pembobotan

\begin{tabular}{|c|c|c|c|c|c|c|}
\hline Cause & Penyebab Masalah & CODE & $\mathbf{S}$ & $\mathbf{O}$ & D & RPN \\
\hline \multirow{6}{*}{ Man } & Keterlambatan pengembalian & $2 \mathrm{C}$ & 9 & 5 & 9 & 405 \\
\hline & $\begin{array}{l}\text { Pelaksanaan evaluasi harian belum di } \\
\text { optimalkan }\end{array}$ & 2B & 6 & 5 & 9 & 270 \\
\hline & $\begin{array}{l}\text { Operator menjalankan work order secara } \\
\text { acak }\end{array}$ & $1 \mathrm{E}$ & 5 & 5 & 8 & 200 \\
\hline & Jarangnya pengecekan oleh leader dan & & & & & \\
\hline & quality assurance & 1D & 6 & 4 & 8 & 192 \\
\hline & Prosedur yang ada kurang ditegaskan & $2 \mathrm{~A}$ & 6 & 5 & 6 & 180 \\
\hline \multirow{4}{*}{ Method } & Peminjaman tool oleh/ke area assembly lain & $3 \mathrm{~A}$ & 7 & 3 & 5 & 105 \\
\hline & Tidak menggunakan tool bag & $1 \mathrm{C}$ & 4 & 3 & 6 & 72 \\
\hline & siluet antar tool sejenis hampir sama & $2 \mathrm{D}$ & 5 & 6 & 2 & 60 \\
\hline & Kedisiplinan kurang & $1 \mathrm{~B}$ & 3 & 3 & 5 & 45 \\
\hline Enviorment & $\begin{array}{l}\text { Kesadaran akan akibat yang ditimbulkan masih } \\
\text { rendah }\end{array}$ & $1 \mathrm{~A}$ & 4 & 3 & 3 & 36 \\
\hline
\end{tabular}


Tabel 2. Hasil Persentase Kumulatif

\begin{tabular}{cccc}
\hline $\begin{array}{c}\text { Penyebab } \\
\text { Masalah }\end{array}$ & $\begin{array}{c}\text { RPN } \\
\text { Score }\end{array}$ & \% & $\begin{array}{c}\text { Commulative } \\
\text { \% }\end{array}$ \\
\hline 2C & 405 & $25.88 \%$ & $25.88 \%$ \\
2B & 270 & $17.25 \%$ & $43.13 \%$ \\
1E & 200 & $12.78 \%$ & $55.91 \%$ \\
1D & 192 & $12.27 \%$ & $68.18 \%$ \\
2A & 180 & $11.50 \%$ & $79.68 \%$ \\
3A & 105 & $6.71 \%$ & $86.39 \%$ \\
1C & 72 & $4.60 \%$ & $90.99 \%$ \\
2D & 60 & $3.83 \%$ & $94.82 \%$ \\
1B & 45 & $2.88 \%$ & $97.70 \%$ \\
1A & 36 & $2.30 \%$ & $100.00 \%$ \\
\hline TOTAL & $\mathbf{1 5 6 5}$ & & \\
\hline
\end{tabular}

Tabel 3. Prioritas Masalah

\begin{tabular}{cl}
\hline Code & \multicolumn{1}{c}{ Penyebab Masalah } \\
\hline 3A & Peminjaman tool oleh/ke area assembly lain \\
1C & Tidak menggunakan tool bag \\
2D & siluet antar tool sejenis hampir sama \\
1B & Kedisiplinan kurang \\
1A & Kesadaran akan akibat yang ditimbulkan masih rendah \\
\hline
\end{tabular}

\subsection{Penerapan 5S}

Berikut ini merupakan usulan dari pendekatan 5S (Seiri, Seiton, Seiso, Seiketsu, dan Shitsuke).

\begin{tabular}{cll}
\hline Aspek & \multicolumn{1}{c}{ Keadaan } & \multicolumn{1}{c}{ Usulan } \\
\hline Seiri & Tool maupun & \multicolumn{1}{c}{ Operator meminjam dan mengembalikan tool sesuai work } \\
(Ringkas) & $\begin{array}{l}\text { perlengkapan lain yang } \\
\text { tidak digunakan hanya } \\
\text { diletakkan sembarangan }\end{array}$ & $\begin{array}{l}\text { order saat itu untuk memperingkas keadaan area produksi } \\
\text { dan mempersedikit jumlah tool di tool bag agar } \\
\text { mempermudah membedakan tool tersebut. }\end{array}$ \\
& & $\begin{array}{l}\text { Hal ini juga berpengaruh ketika operator lain ingin } \\
\text { menggunakan tool sehingga tidak harus mencari operator } \\
\text { yang sedang meminjam }\end{array}$ \\
\hline $\begin{array}{ll}\text { Seiton } \\
\text { (Rapi) }\end{array}$ & $\begin{array}{l}\text { Terkadang ketika } \\
\text { operator mengembalikan } \\
\text { tool tidak sesuai dengan } \\
\text { siluetnya }\end{array}$ & $\begin{array}{l}\text { Siluet yang terdapat di trolley area produksi diberi label } \\
\text { sesuai dengan nama tool nya sehingga mempermudah } \\
\text { operator dalam meminjam dan mengembalikan tool seperti } \\
\text { pada Gambar 5. }\end{array}$
\end{tabular}

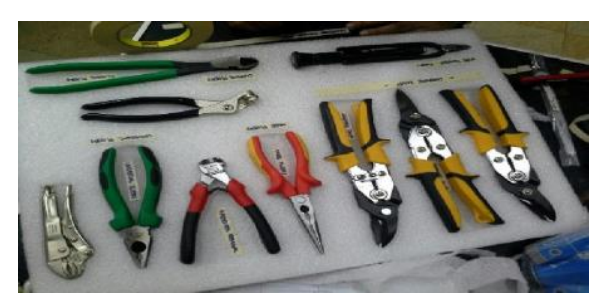

Gambar 5. Silhouette Dengan Nama

Seiso Beberapa tool tidak Banyak sekali tool yang sama pada area produksi sehingga (Resik) diketahui tempat rawan akan terjadi kekeliruan pengembalian. Sehingga pengambilannya sebelum tool/trolley masuk ke area produksi keduanya (trolley) karena belum harus ditandai dengan tanda yang sama (biasanya terdapat tanda. menggunakan warna) sehingga meminimalisir operator yang salah dalam pengembalian tool. 


\begin{tabular}{|c|c|c|}
\hline Aspek & Keadaan & Usulan \\
\hline $\begin{array}{l}\text { Seiketsu } \\
\text { (Rawat) }\end{array}$ & $\begin{array}{l}\text { Prosedur peminjaman } \\
\text { tool yang berlaku tidak } \\
\text { diterapkan oleh operator } \\
\text { sehingga perlu adanya } \\
\text { tindakan. Hal tersebut } \\
\text { untuk menjaga agar } \\
\text { standarisasi perusahaan } \\
\text { tetap terjaga. }\end{array}$ & $\begin{array}{l}\text { Ada beberapa cara yang dapat dilakukan untuk mengatasi } \\
\text { masalah ini seperti pengadaan sosialisasi, Sosialisasi } \\
\text { dilakukan dalam rangka untuk meningkatkan kesadaran } \\
\text { akan akibat yang ditimbulkan sehingga operator/karyawan } \\
\text { dapat memahami jika ketentuan dan prosedur yang berlaku } \\
\text { lebih memberikan konsep keselamatan dan kesehatan } \\
\text { bukan pembatasan maupun ancaman. Dengan pemahaman } \\
\text { tersebut operator/karyawan dapat mengerti akan hubungan } \\
\text { dari prosedur yang berlaku dengan proses bekerja di area } \\
\text { produksi. } \\
\text { Sosialisasi tersebut seperti: } \\
\text { a. Sosialisasi mengenai dampak yang diakibatkan ketika } \\
\text { operator tidak menggunakan tanda peminjaman tool } \\
\text { sehingga tidak dapat diidentifikasi keberadaan tool } \\
\text { yang dampaknya berbalik lagi terhadap operator harus } \\
\text { melakukan pembongkaran bagian pesawat. } \\
\text { b. Sosialisasi mengenai penggunaan tool bag sehingga } \\
\text { banyak tool yang tertinggal di area produksi. }\end{array}$ \\
\hline $\begin{array}{c}\text { Shitsuke } \\
\text { (Rajin) }\end{array}$ & $\begin{array}{l}\text { Pengecekan trolley oleh } \\
\text { gudang, leader dan } \\
\text { quality assurance masih } \\
\text { jarang dilakukan. } \\
\text { Pemberlakuan ketegasan } \\
\text { kepada operator pun } \\
\text { masih kurang. }\end{array}$ & $\begin{array}{l}\text { Penegasan disini berupa dengan adanya kebijakan. } \\
\text { Kebijakan yang berlaku harus diperjelaskan sebagai } \\
\text { maksud bukan untuk mengancam operator tetapi untuk } \\
\text { menegakkan kewajiban dan prosedur yang berlaku. } \\
\text { Penegakan tersebut hanya sebagai salah satu syarat agar } \\
\text { terciptanya suatu hubungan yang berkesinambungan antara } \\
\text { perusahaan dan karyawan. Punishment dari pelanggaran } \\
\text { kebijakan tersebut bertujuan agar operator tidak melakukan } \\
\text { kesalahan yang berawal dari kebiasaan yang kurang disiplin } \\
\text { tersebut. Akan tetapi kebijakan tersebut harus senantiasa } \\
\text { didampingi dengan pengawasan baik dari tim di area } \\
\text { produksi, gudang maupun quality assurance agar pola } \\
\text { kebiasaan yang saat ini tertanam dalam diri operator dapat } \\
\text { berubah. Selain itu, kebijakan juga ditekankan kepada diri } \\
\text { pribadi leader/supervisor untuk melakukan pengecekan } \\
\text { disaat evaluasi harian berlangsung, seperti pengembalian } \\
\text { tool ke trolley supaya dapat diketahui tool mana yang belum } \\
\text { ada. Hal tersebut dimaksudkan supaya dapat diidentifikasi } \\
\text { maupun mengklarifikasi operator yang menggunakan atau } \\
\text { meminjam tool tersebut. }\end{array}$ \\
\hline
\end{tabular}

Bentuk punishment antara lain: kehilangan pekerjaan, tidak menerima kenaikan gaji, dihapus dari daftar karyawan yang akan dipromosi, penghinaan publik, kegagalan mendapatkan reward, ancaman pemecatan, dan lain sebagainya. Selain ada punishment juga terdapat reward untuk para karyawan yang memiliki kinerja yang baik. Pemberian reward berdasarkan kinerja berupa gaji tergolong dalam extrinsic reward, dimana reward tersebut berasal pekerjaan, tetapi bukan merupakan bagian dari pekerjaan. Selain gaji, bentuk extrinsic reward lainnya berupa bonus, benefit, interpersonal rewards (pengakuan/status), dan promosi.

\subsection{Hasil Penerapan 5S}

Berdasarkan hasil uji coba penerapan 5S yang dilakukan hanya seiton (rapi) dan seiso (resik) yang dapat diterapkan di perusahaan. Berikut ini merupakan rincian dari hasil penerapan $5 \mathrm{~S}$ 


\begin{tabular}{|c|c|c|}
\hline Aspek & Status & Keterangan \\
\hline $\begin{array}{l}\text { Seiri } \\
\text { (Ringkas) }\end{array}$ & Belum dapat diterapkan & $\begin{array}{l}\text { Kebiasaan yang biasanya dilakukan oleh operator menjadikan hal tersebut } \\
\text { sebuah culture organization ters endiri sehingga untuk mengubah hal } \\
\text { tersebut diperlukan pengawasan dalam keberjalannanya. }\end{array}$ \\
\hline $\begin{array}{l}\text { Seiton } \\
\text { (Rapi) }\end{array}$ & Dapat diterapkan & - \\
\hline $\begin{array}{l}\text { Seiso } \\
\text { (Resik) }\end{array}$ & Dapat diterapkan & - \\
\hline $\begin{array}{l}\text { Seiketsu } \\
\text { (Rawat) }\end{array}$ & Belum dapat diterapkan & $\begin{array}{l}\text { Sosialisasi secara keseluruhan belum dapat dilakukan karena jadwal dari } \\
\text { waktu produksi yang diperketat untuk mengejar delay schedul. }\end{array}$ \\
\hline $\begin{array}{l}\text { Shitsuke } \\
\text { (Rajin) }\end{array}$ & Belum dapat diterapkan & $\begin{array}{l}\text { Kekurangan personil di dalam tim gudang sehingga pembebanan tugas } \\
\text { lebih dapat membuat tugas yang lain keteteran. }\end{array}$ \\
\hline
\end{tabular}

\section{KESIMPULAN}

Berikut ini merupakan kesimpulan yang didapatkan dari hasil pengolahan data dan analisis penelitian yang telah dilakukan:

a. Dari hasil cause-effect diagram didapatkan 10 penyebab masalah yang mempengaruhi terjadinya lost tool di final assembly di PT. XYZ, yaitu operator menjalankan work order secara acak, kedisiplinan operator kurang, kesadaran akan akibat yang ditimbulkan masih rendah, operator jarang memakai/menggunakan tool bag, jarangnya pengecekan dari leader dan quality assurance, prosedur yang ada kurang ditegaskan, pelaksanaan evaluasi harian belum dioptimalkan, siluet antara tool sejenis hampir sama, keterlambatan pengembalian tool dan terjadi peminjaman tool oleh/ke area assembly lain.

b. Dengan diagram pareto dan nilai risk priority number (RPN) diketahui 5 penyebab (cause) masalah yang menjadi fokus perusahaan yaitu peminjaman tool oleh/ke area assembly lain dengan nilai RPN 105, operator tidak/jarang menggunakan tool bag dengan nilai RPN 72, siluet antara tool sejenis hampir sama sama dengan nilai RPN 60, kedisiplinan operator kurang dengan nilai RPN 45 dan kesadaran akan akibat yang ditimbulkan masih rendah dengan nilai RPN 36.

c. Hasil penerapan 5S yang dilakukan hanya aspek seiton (rapi) dan seiso (resik) yang baru bisa dilakukan oleh perusahaan.

\section{DAFTAR PUSTAKA}

[1] Litawati. 2007. "Usulan Perbaikan Cara Kerja dengan Tangan Kiri Tangan Kanan dan Sistem Kerja 5S pada Perakitan Sepatu Wanita Buccheri di PT. Vigano Cipta Persada". Jakarta: Universitas Bina Nusantara.

[2] Hartatik, I. P. (2014). Buku Pintar Membuat SOP. Yogyakarta: Flashbooks

[3] Glaser, B. G., \& Strauss, A. L. (1967). The Discovery of Grounded Theory: Strategies for Qualitative Research. Chicago, IL: Aldine.

[4] Gasperz, V. (2007). ISO 9001:2000 and Contunial Quality Improvement. Jakarta: PT. Gramedia Pustaka Utama.

[5] Gasperz, V. (2011). Lean Six-Sigma for Manufacturing and Service Industries. Bogor: Penerbit Vinchristo Publication.

[6] Gasperz, V. (2012). All in One Management Tool Book. Bogor: Tri-Al Bros Publishing.

[7] Womark, J. P., \& Jones, D. T. (1996). Lean Thinking: Banish Waste and Create Wealth in Your Corporation. New York: Simon \& Scuster.

[8] Scarvada, A. J., Chameeva, T.B., Hays, J. M., Hill, A.J. 2004. "A review of the Causal Mapping Practice and Research Literature". Second World Conference on POM and 15th Annual POM Conference. Mexico

[9] Susilo and V.R. Kaho. (2010). Manajemen Risiko Berbasis ISO 31000 Untuk Industri Non Perbankan. Jakarta: Penerbit PPM

[10] Ab-Rahman, Khamis, N., et al. (2010). "Implementation of 5S practices in the Manufacturing Companies: A Case Study". American Journal of Applied Sciences, 1182-1189.

[11] Gurel, D. A. 2013. "A conceptual Evaluation Of 5S Model in Hotels, African Journal of Business Management". 3035-3042

[12] Bayo-Morines, Bello-Pintado, A., Merino -Diaz de Cerio, J. 2010. "5S Use in Manufacuring Plants: Contextual Factors and Impact on Operating Performance. International Journal of Quality and Reliability Management. 217-230

[13] Douglas. 2002. "Improving Manufacturing Performance". The American Society for Quality (ASQ) 56 th Annual Congress.

[14] Burns, T. and Stalker, G.M. (1961). The Management of Innovation. London: Tavistock Publications. 